\title{
Experimental and Numerical Investigations of Air Cooling for a Large-Scale Motor
}

\author{
Chih-Chung Chang, ${ }^{1}$ Chiao-Hung Cheng, ${ }^{1}$ Ming-Tsun Ke, ${ }^{2}$ and Sih-Li Chen ${ }^{1}$ \\ ${ }^{1}$ Department of Mechanical Engineering, National Taiwan University, Taipei 106, Taiwan \\ ${ }^{2}$ Department of Energy and Refrigerating Air-Conditioning Engineering, National Taipei University of Technology, \\ Taipei 106, Taiwan
}

Correspondence should be addressed to Sih-Li Chen, slchen01@ntu.edu.tw

Received 19 May 2009; Accepted 19 May 2009

Recommended by Wei Tong

This article experimentally and numerically investigates the thermal performance of a 2350-kW completely enclosed motor, which is cooled through an air-to-air heat exchanger. The air in the heat exchanger includes external and internal flow paths. The external air driven by the rotation of the centrifugal fan goes through the heat exchanger mounted on the top of the frame. The internal air absorbs heat released from the stator and the rotor and then transfers the heat to the heat exchanger through the motion of two axial fans and the rotor. Several test rigs have been set up to measure the performance of the fan and the motor. The Fluent software package is adopted to analyze the complicated thermal-fluid interactions among the centrifugal fan, two axial fans, heat exchanger, stator, and rotor. The measured data, including the fan performance curves and the temperature profiles of the heat exchanger and the stator, show good agreement with the simulated results. The numerical calculations also show that the nonuniform external flow distribution through the heat exchanger and the air leakage between the axial fan and the rotor reduces the cooling ability of the motor. A detailed discussion is also included to improve the motor cooling performance.

Copyright ( 92009 Chih-Chung Chang et al. This is an open access article distributed under the Creative Commons Attribution License, which permits unrestricted use, distribution, and reproduction in any medium, provided the original work is properly cited.

\section{Introduction}

Thermal dissipation becomes a key consideration in the operation of large motors, since overheating will result in a decrease of the motor's lifetime. Having information for the flow and temperature fields inside the heat exchangers and the temperature distributions of rotor and stator through experimental testing is expensive and difficult. Therefore, a Computational Fluid Dynamics (CFD) software package is useful for investigating the complicated thermal-fluid interaction problems inside the motor.

Many papers have used CFD simulation methods and experimental testing methods to investigate the performances of the fan and the small motor. Amaon et al. [1] applied experimental testing and simulation to explore the unsteady flow generated by an axial fan. Younsi et al. [2] performed numerical and experimental analyses to discuss the influence of impeller geometry on the unsteady flow in a centrifugal fan. Asuaje et al. [3] and Zhou et al. [4] used computational fluid dynamics to predict the flow and pressure fields in the centrifugal pump. In addition, optimization of the fan performance was also investigated through the theory model [5]. Liao et al. [6,7] provided CFD results for thermal and flow analysis to optimize the thermal performance of the motor. Wu et al. [8] adopted computational and experimental results to analyze the thermal performance of small electric motors. However, the simulation results in small motors cannot be applied to large motors.

The present article experimentally and numerically investigates the thermal performance of a large motor with a capacity of $2350 \mathrm{~kW}$. The article is divided into three parts. In the first part, the performances of centrifugal and axial fans are demonstrated in order to provide the performance curves for motor simulation. Then, the temperature distributions of the heat exchanger and motor stator are simulated and compared with the experimental data. Finally, the whole motor's flow fields, pressure fields, and temperature profiles in the stator and rotor are discussed. A strategy to improve the thermal performance of the motor is also proposed. 


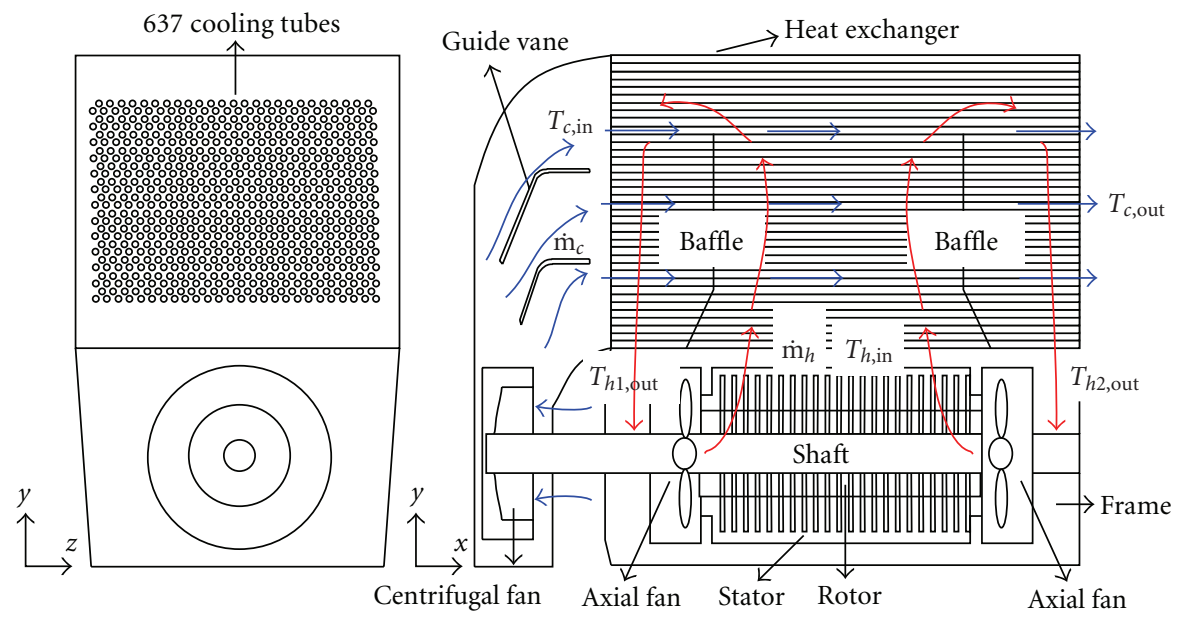

FIGURE 1: Schematic view of flow paths and components for the motor.

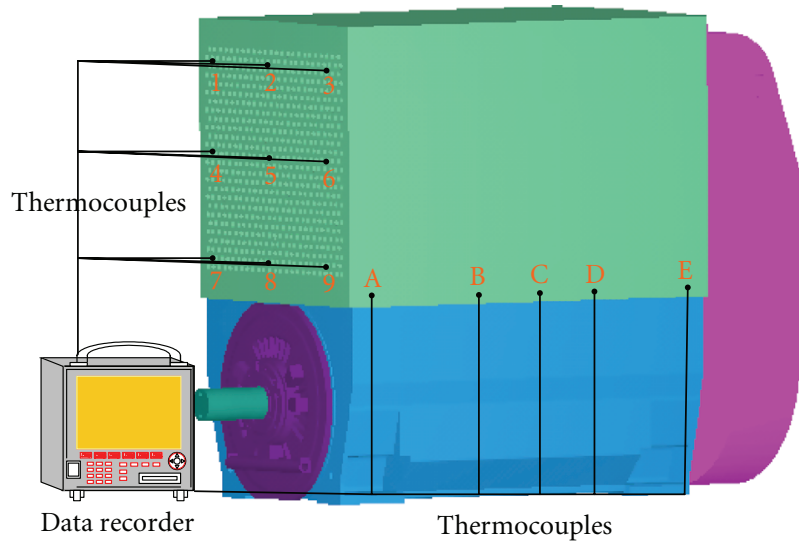

FIgURe 2: Measurement locations of the heat exchanger for the airto-air cooled motor.

\section{Experimental Testing and Simulations}

In this study, the $2350-\mathrm{kW}$ completely enclosed air-toair cooled motor with dimensions $2435 \mathrm{~mm} \times 1321 \mathrm{~mm} \times$ $2177 \mathrm{~mm}$, as shown in Figure 1, is investigated. The motor includes a centrifugal fan, two axial fans, a shaft, a stator, a rotor, and a heat exchanger with 637 cooling tubes. There are two flow paths in the heat exchanger: the internal and external flows. As shown with the blue arrows, the external flow is driven by the rotation of the centrifugal fan, which is mounted externally to the frame on the motor shaft. The external air flows through the 637 tubes of the staggered heat exchanger mounted on top of the motor. The red arrows in Figure 1 show the internal air circulated by two axial fans on each side of the shaft and cooled by the heat exchanger.

Several test rigs have been set up to measure the performance of the centrifugal fan, axial fan, and motor. The centrifugal fan with twelve blades and the axial fan with nine blades are first tested through a Chinese National Standards (CNSs) 2726 test apparatus. The purposes of these tests are to get the fan performance curves and compare them

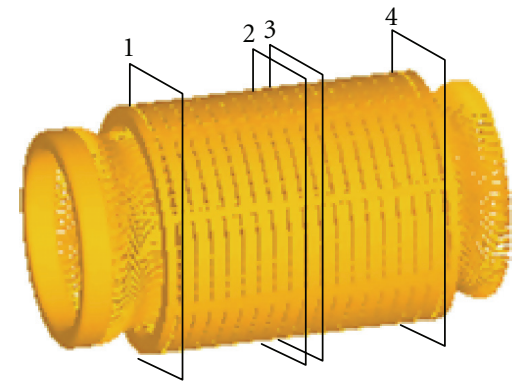

FIGURE 3: Schematic illustration of each cross section for the rotor and stator.

with the numerical results. The temperature measurement locations at the heat exchanger and stator are demonstrated in Figures 2 and 3. Figure 2 shows the three-dimensional (3D) view of the enclosed air-to-air cooled motor. It indicates the measured temperature locations of the external air from number 1 to 9 and of the internal air from letter $A$ to $E$ in the heat exchanger. Figure 3 illustrates the four cross sections at the stator to measure the average temperatures. This includes the iron core temperatures at cross Sections 2 and 3 and the copper winding temperatures at cross Sections 1 and 4 . Adjusting the power supply offers the necessary power to the system with a rotating speed of $1800 \mathrm{rpm}$. The flow rate of the external air is measured by the anemometer at the outlet of the 637 cooling tubes.

The Fluent commercial software package is adopted to simulate the flow, pressure, and temperature fields of the 2350-kW enclosed air-to-air cooled motor. Due to the complex geometry of this motor, unstructured or hybrid meshes are employed. Testing the grid density is also necessary to confirm the accuracy of the numerical results. The physical model is assumed to be an incompressible flow with constant properties. In the calculation, the $k-\varepsilon$ turbulent model with suitable boundary conditions is adopted by using an implicit segregated steady-state solver. With a rotating speed of $1800 \mathrm{rpm}$, the package function of moving the 


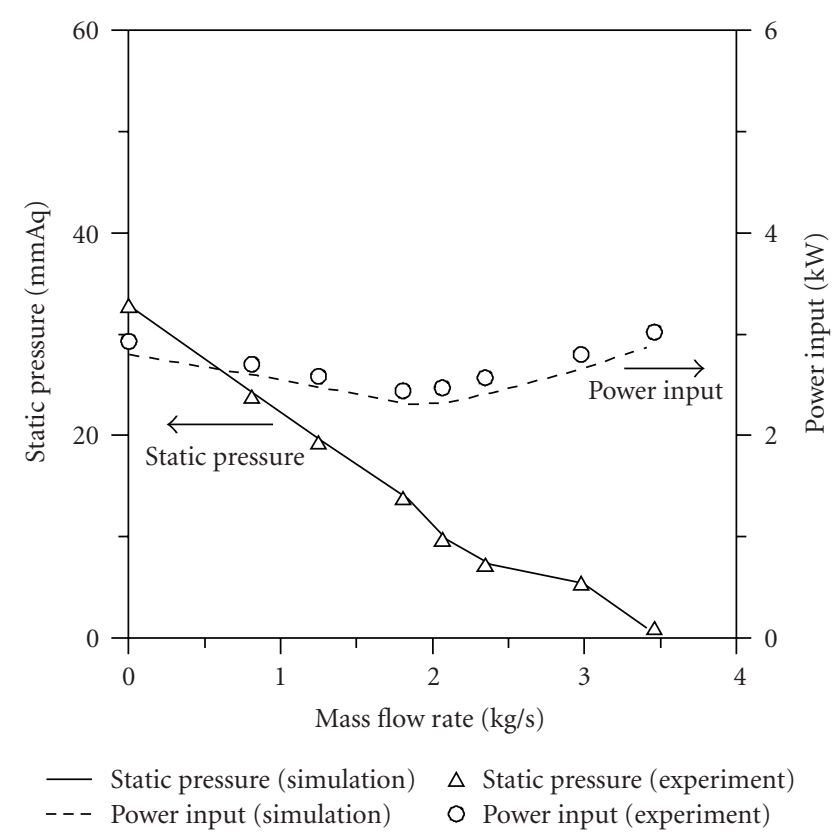

(a) Axial fan

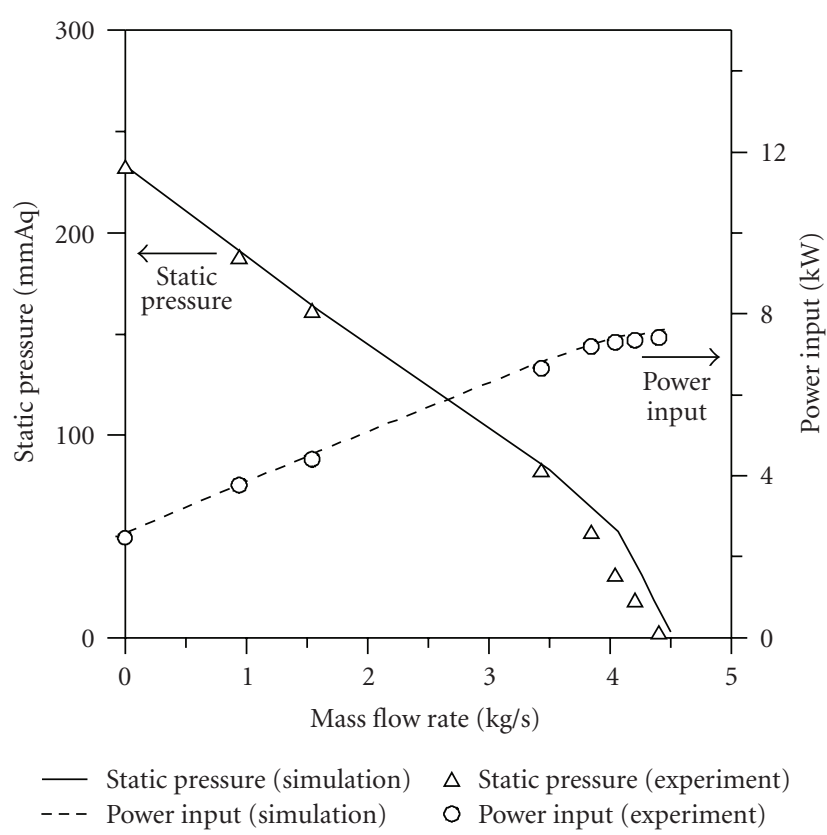

(b) Centrifugal fan

Figure 4: Performance curves for (a) axial fan and (b) centrifugal fan.

reference frame replaces the motion of the two axial fans, rotor, and shaft. For the temperature calculation, the energy function is actuated in the simulated process. In addition, a second upward scheme is used to get more accurate results. The under-relaxation parameters are set at 0.3 for pressure and $0.6-1$ for momentum, $k-\varepsilon$, and energy. A calculation is converged when the residuals are below the specified convergence criterion.

\section{Results and Discussion}

In this section, the performance of the axial fan, centrifugal fan, heat exchanger, stator, and rotor will be discussed. The simulated results will be compared with the experimental data to verify the numerical predictions. Then, modifications of the present design are also proposed to enhance the thermal performance of the $2350-\mathrm{kW}$ enclosed air-to-air cooled motor.

3.1. Fans. Figures 4(a) and 4(b) indicate the variations of static pressure and power input at different mass flow rates for the axial fan and the centrifugal fan, respectively. As the static pressure of the axial fan decreases from $32.8 \mathrm{mmAq}$ to $0.9 \mathrm{mmAq}$, the calculated mass flow rate changes from $0 \mathrm{~kg} / \mathrm{s}$ to $3.4 \mathrm{~kg} / \mathrm{s}$. When the static pressure of the centrifugal fan decreases from $232 \mathrm{mmAq}$ to $2.6 \mathrm{mmAq}$, the calculated mass flow rate increases from $0 \mathrm{~kg} / \mathrm{s}$ to $4.49 \mathrm{~kg} / \mathrm{s}$. The computed mass flow rates of the axial and centrifugal fans are $2 \%$ and $6 \%$ greater than the experimental data.

The power input is calculated from

$$
O_{p}=\omega \mathrm{M},
$$

where $O_{p}$ is the power input, $\omega$ is the angular velocity of the fan, and $M$ is the torque imposed on the fan. As shown in Figure 4, the power input of the axial fan at the mass flow rate of $3.4 \mathrm{~kg} / \mathrm{s}$ has the highest value, which is $2.87 \mathrm{~kW}$, and at the mass flow rate of $1.836 \mathrm{~kg} / \mathrm{s}$ has the lowest value, which is $2.31 \mathrm{~kW}$. The power input of the centrifugal fan has the largest value of $7.64 \mathrm{~kW}$ at the mass flow rate, $4.49 \mathrm{~kg} / \mathrm{s}$, and the smallest value of $2.6 \mathrm{~kW}$ at the zero mass flow rate. Compared with the experimental data, the deviation of the calculated power output is $6 \%$ for the axial fan and $5 \%$ for the centrifugal fan.

The fan performances at different speeds from $1500 \mathrm{rpm}$ to $3600 \mathrm{rpm}$ are also calculated. The results of the flow rates and torques of the axial fan vary from $0.99 \mathrm{~m}^{3} / \mathrm{s}$ to $4.73 \mathrm{~m}^{3} / \mathrm{s}$ and from $8.3 \mathrm{~N}-\mathrm{m}$ to $51.6 \mathrm{~N}-\mathrm{m}$, respectively. The results of the flow rates and torques of the centrifugal fan are from $2.67 \mathrm{~m}^{3} / \mathrm{s}$ to $7.37 \mathrm{~m}^{3} / \mathrm{s}$ and from $30.6 \mathrm{~N}-\mathrm{m}$ to $174.4 \mathrm{~N}-\mathrm{m}$, respectively. According to the fan laws, the mass flow rate is linearly proportional to the rotating speed. The torque is related to the square of the rotating speed. The simulated results follow the fan laws. From the fan law equation, the axial fan performance and the centrifugal fan performance can be predicted at other rotation speeds. Then, the equations of the axial fan can be expressed as follows:

$$
\begin{aligned}
Q & =0.001 N, \\
M & =1 \times 10^{-6} N^{2.12} .
\end{aligned}
$$

The equations of the centrifugal fan can be shown as follows:

$$
\begin{aligned}
Q & =0.002 N, \\
M & =2 \times 10^{-5} N^{1.98},
\end{aligned}
$$


TABLE 1: Table Heat generation rates.

\begin{tabular}{lc}
\hline Total loss (W) & 78930 \\
\hline Stator winding loss (W) & 23400 \\
Rotor winding loss (W) & 8200 \\
Stator core loss (W) & 21310 \\
Rotor core loss (W) & 6520 \\
Other loss (W) & 19500 \\
\hline
\end{tabular}

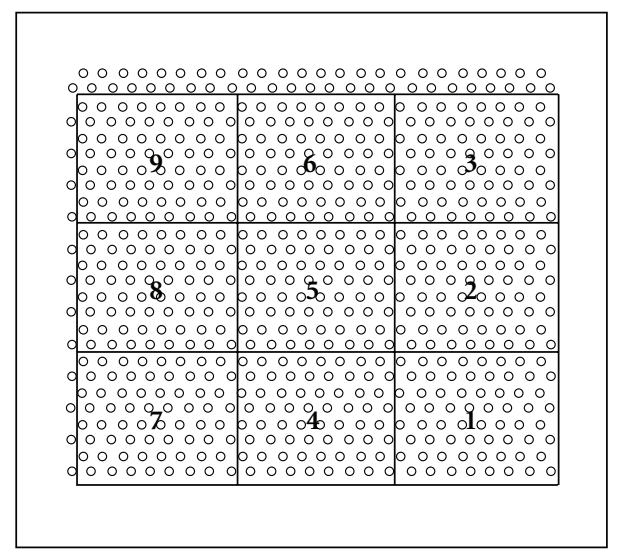

FIGURE 5: Block numbers for the external air in heat exchanger.

where $Q$ is the volumetric flow rate and $N$ is the rotation speed. Equations (2)-(5) will be applied to the Fluent software package to simulate the $3 \mathrm{D}$ motor cooling performance.

It is also observed from the simulated results that the flow field at the large fan static pressure exhibits reversed flow between the blades, which collides with the blade surface and reduces the effective flow area. These surge phenomena decrease the motor cooling capacity. When the fan static pressure is small, the air between the blades goes through the blade surface smoothly.

3.2. Heat Exchanger. To observe the flow distributions of the external air through the heat exchanger, the outlet of the cooling tubes is specified with nine blocks, as shown in Figure 5. Each block includes 64 cooling tubes. Because the flow fields in the original design have nonuniform phenomena, we also provide a new design for the guide vanes. Figures $6(\mathrm{a})$ and $6(\mathrm{~b})$ illustrate the guide vanes of the original and modified designs. After the design is modified, the number of guide vanes changes from two to four in Figure 6(b). Figure 7 presents the mass flow rate distributions. The mass flow rate in each block of the heat exchanger obviously exhibits nonuniform distributions in the original design. The external air mainly concentrates on blocks 1 and 7, while blocks 2, 5, and 8 have a lower mass flow rate. The comparison between the experimental and calculated results is about $6 \%$ precision. As shown in Table 2, the simulated results of the mass flow rate in the modified design have more uniform behavior than that of the original design.

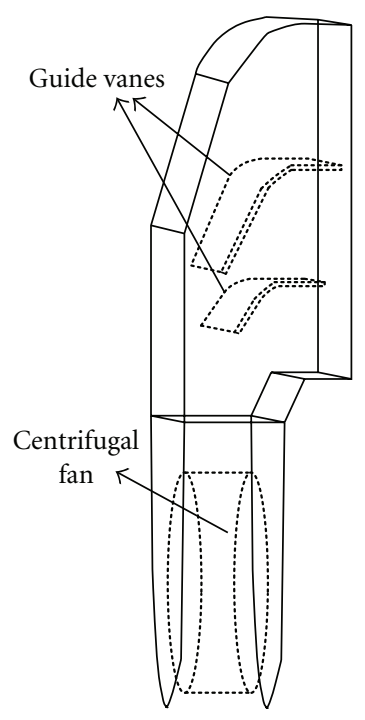

(a) Original design

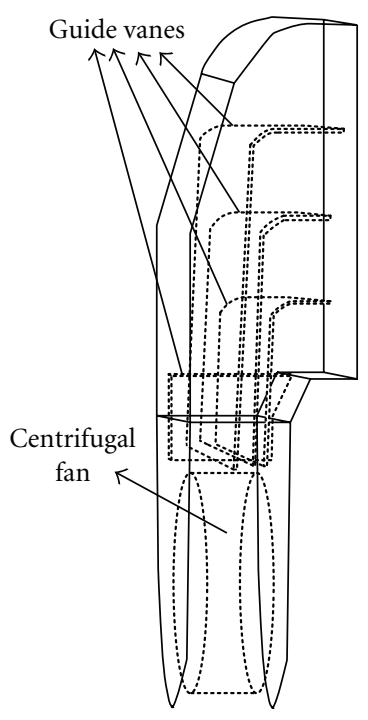

(b) Modified design
Figure 6: Guide vanes with (a) original design and (b) modified design.

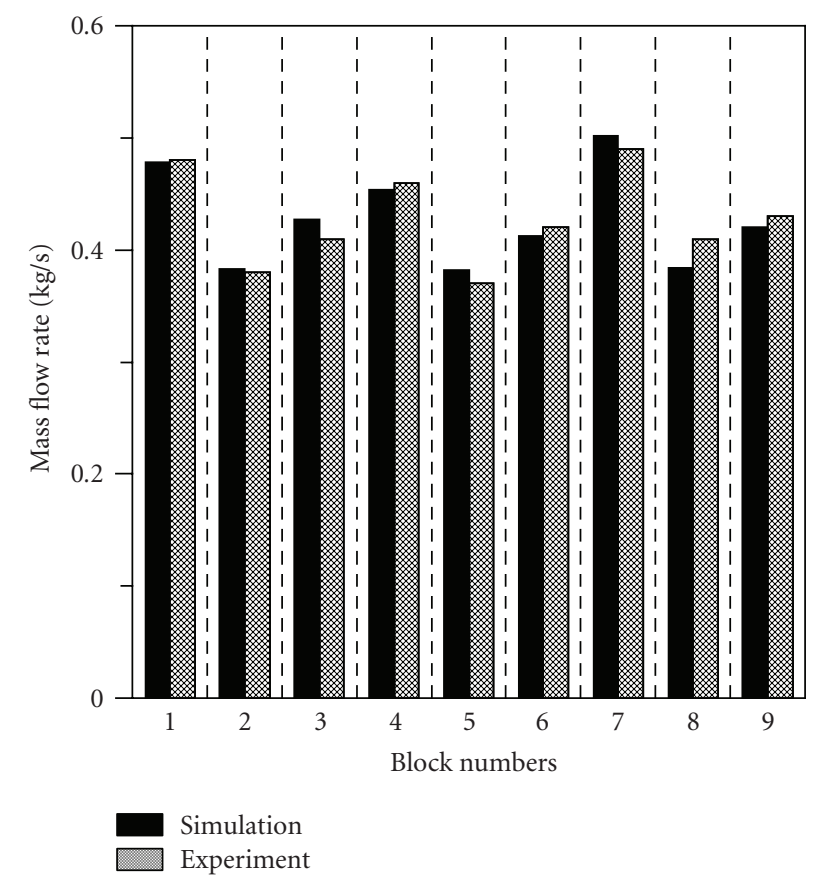

Figure 7: Mass flow rates for the external flow under different block numbers for the original design.

The temperature profiles at the heat exchanger are also obtained from the model predictions and experiment testing. The lump model and 3D model are adopted to predict the thermal performance of the heat exchanger. The lump energy balance equation for the external air in the heat exchanger is

$$
q=\dot{m}_{c} C_{p}\left(T_{c, \text { out }}-T_{c, \text { in }}\right),
$$

where $q$ is the total heat generation rate, $\dot{m}_{c}$ is the mass flow rate of the external air, $C_{p}$ is the specific heat, $T_{c, \text { out }}$ is the air 
TABLE 2: Mass flow rates for the external flow under different block numbers.

\begin{tabular}{ccc}
\hline Block number & Mass flow rates $(\mathrm{kg} / \mathrm{s})($ original design $)$ & Mass flow rates $(\mathrm{kg} / \mathrm{s})(\mathrm{modified} \mathrm{design})$ \\
\hline 1 & 0.48 & 0.42 \\
2 & 0.38 & 0.43 \\
3 & 0.43 & 0.43 \\
4 & 0.45 & 0.44 \\
5 & 0.38 & 0.42 \\
6 & 0.41 & 0.43 \\
7 & 0.50 & 0.43 \\
8 & 0.38 & 0.42 \\
9 & 0.42 & 0.42 \\
\hline
\end{tabular}

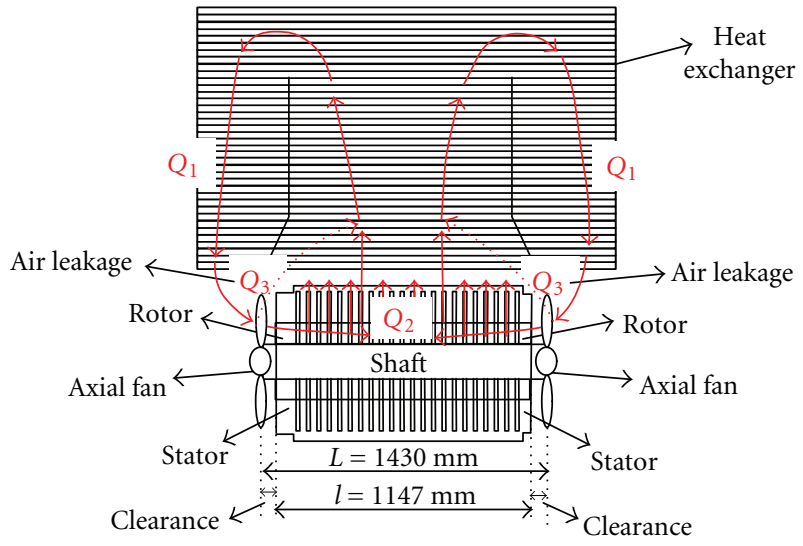

FIGURE 8: Air leakage from the clearance between axial fan and stator.

outlet temperature, and $T_{c, \text { in }}$ is the air inlet temperature. The energy equation of the heat exchanger can also be written as

$$
q=U A \frac{\left(T_{h, \text { out }}-T_{c, \text { in }}\right)-\left(T_{h, \text { in }}-T_{c, \text { out }}\right)}{\ln \left(\left(T_{h, \text { out }}-T_{c, \text { in }}\right) /\left(T_{h, \text { in }}-T_{c, \text { out }}\right)\right)},
$$

where $U$ is the overall heat transfer coefficient, which can be obtained from the heat transfer coefficients of convection and conduction $[9,10]$. In (7), $A$ is the heat transfer area, $T_{h, \text { in }}$ is the internal air inlet temperature, and $T_{h, \text { out }}$ is the internal air outlet temperature.

In the lump model calculation, the total heat generation rate in this motor is $78930 \mathrm{~W}$, as shown in Table 1. In Table 3 , the inlet temperature of the external air is $28^{\circ} \mathrm{C}$, and the mass flow rate is $4.4 \mathrm{~kg} / \mathrm{s}$, which are determined from the experimental data. Based on the lump model, the outlet air temperature is $46^{\circ} \mathrm{C}$, which is smaller than $4^{\circ} \mathrm{C}$ in comparison with the experimental results. According to (7), the inlet and outlet temperatures of the internal flow are calculated as $97^{\circ} \mathrm{C}$ and $60^{\circ} \mathrm{C}$, respectively. Compared with the experimental results, the outlet temperature is the same, and the inlet temperature is $6^{\circ} \mathrm{C}$ higher.

In addition to the lump model calculation, the temperature fields of the original and modified designs on the basis of the 3D heat exchanger model are also calculated using the Fluent software package. As listed in Table 3, the air inlet temperatures of the external and internal air are

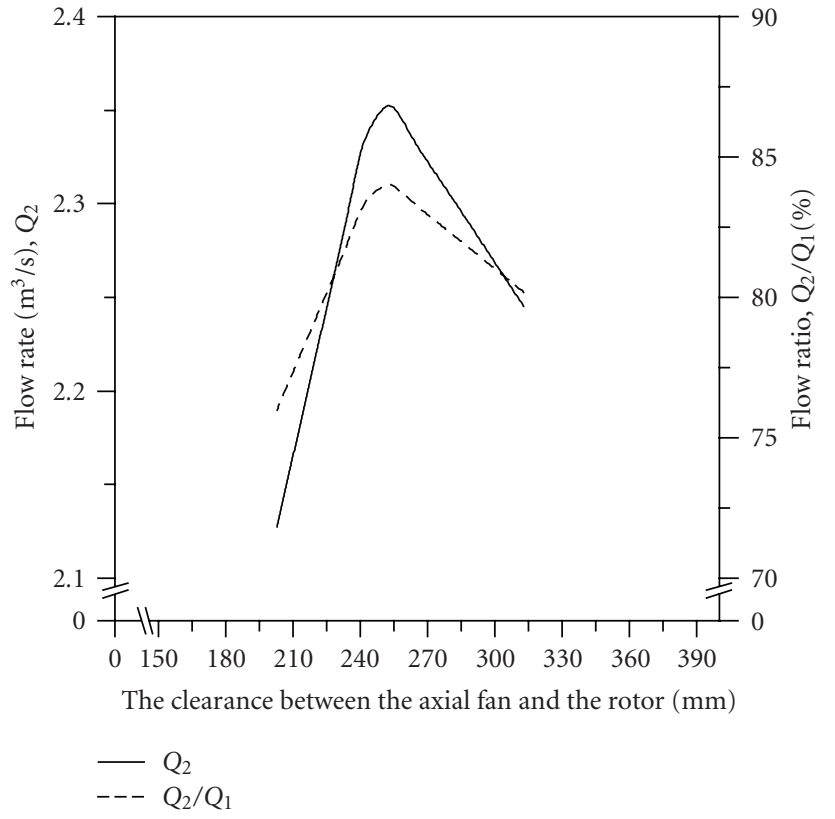

FIGURE 9: Effect of the clearance between the rotor and the axial fan to flow rate $Q_{2}$ and flow ratio $Q_{2} / Q_{1}$.

$28^{\circ} \mathrm{C}$ and $91^{\circ} \mathrm{C}$, which are from the experimental results. From the calculated results of the original design, the air outlet temperatures of the external flow and the internal flow are $49^{\circ} \mathrm{C}$ and $61^{\circ} \mathrm{C}$. The comparison between the experimental and calculated results is about $8 \%$ precision. For the modified design, the air outlet temperature of the external flow increases to $52^{\circ} \mathrm{C}$, and the air outlet temperature of the internal flow decreases to $58^{\circ} \mathrm{C}$, which mean that the uniform velocity distributions through the new guide vane design can improve the cooling ability of the heat exchanger.

3.3. Temperature Profiles of Rotor and Stator. The temperature profiles of the rotor and the stator are predicted from the given flow fields inside the motor. First, we use the Fluent software package to simulate the 3D motor model, including the fans, heat exchanger, stator, and rotor, at the conditions of constant temperature. The calculated results demonstrate that the flow and pressure fields at the bottom 
TABLE 3: Average inlet and outlet temperatures of internal and external air flows.

\begin{tabular}{lcccc}
\hline \multirow{2}{*}{ Methods } & \multicolumn{2}{c}{ Inlet temperature $\left({ }^{\circ} \mathrm{C}\right)$} & \multicolumn{2}{c}{ Outlet temperature $\left({ }^{\circ} \mathrm{C}\right)$} \\
Internal air & 91 & External air & 28 & \multicolumn{2}{c}{ Internal air } & 61 & 49 \\
\hline 3D model(original design) & 91 & 28 & 58 & 52 \\
3D model(modified design) & 97 & 28 & 60 & 46 \\
Lump model & 91 & 28 & 60 & 50 \\
Experimental measurement & & & & \\
\hline
\end{tabular}

TABLE 4: Numerical and experimental results for the stator temperatures.

\begin{tabular}{|c|c|c|c|c|c|c|}
\hline \multirow{3}{*}{ Cross section } & \multicolumn{3}{|c|}{ Iron core $\left({ }^{\circ} \mathrm{C}\right)$} & \multicolumn{3}{|c|}{ Copper winding $\left({ }^{\circ} \mathrm{C}\right)$} \\
\hline & \multicolumn{2}{|c|}{ Simulation } & \multirow{2}{*}{$\begin{array}{c}\text { Experiment } \\
\text { Original design }\end{array}$} & \multicolumn{2}{|c|}{ Simulation } & \multirow{2}{*}{$\begin{array}{c}\text { Experiment } \\
\text { Original design }\end{array}$} \\
\hline & Original design & Modified design & & Original design & Modified design & \\
\hline 1 & 76 & 73 & - & 120 & 117 & 122 \\
\hline 2 & 112 & 107 & 111 & 146 & 141 & - \\
\hline 3 & 112 & 107 & 111 & 146 & 141 & - \\
\hline 4 & 86 & 81 & - & 131 & 126 & 138 \\
\hline
\end{tabular}

of the whole motor have a smaller flow rate and larger pressure when compared with other locations within the motor, meaning that the temperatures in the lower area of the motor have higher values. Flow profiles calculated from the Fluent software at the rotor and stator serve as the boundary conditions. The heat generation rates of the iron core and copper winding are also given for the rotor and stator, which are listed in Table 1. The temperature profiles of the rotor and stator can be determined from the software calculation.

Table 4 shows the numerical and experimental results for the average temperatures of the iron core and copper winding in the stator. The calculated iron core temperatures at cross Sections 2 and 3 are $112^{\circ} \mathrm{C}$, which are higher than the experimental measurements by $1^{\circ} \mathrm{C}$. The copper winding temperatures at cross Sections 1 and 4 in the experimental results are $112^{\circ} \mathrm{C}$ and $138^{\circ} \mathrm{C}$, which are higher than $2^{\circ} \mathrm{C}$ and $7^{\circ} \mathrm{C}$ in comparison with the calculated results. Table 5 provides the iron core and copper winding average temperatures in the rotor, which are also divided into four cross sections, as shown in Figure 3. Since the cross Sections 1 and 4 are much closer to the axial fans, the average temperatures are lower than those at cross Sections 2 and 3. Moreover, the temperature at cross Section 4 is higher than that at cross Section 1, because the external air absorbs heat from the internal air above cross Section 1 first. Then the air flows above cross Section 4 with lower cooling ability to exchange heat with the internal air, so that $T_{h 2 \text {,out }}$ is higher than $T_{h 1, \mathrm{out}}$, as shown in Figure 1.

Figure 8 illustrates the effect of air leakage on the motor cooling performance. Due to the clearance existing between the axial fan and rotor, the air $Q_{1}$ from the axial fan is equal to the air $Q_{2}$ flowing to the shaft, rotor, and stator and the air leakage $Q_{3}$, as shown with a dashed line, flowing through the clearance. Only the flow rate $Q_{2}$ into the shaft, stator, and rotor has a cooling effect on the motor. Therefore, the leakage effect inside the motor decreases the flow rate of the internal air $Q_{2}$, which influences the cooling capacity of the motor. To overcome this problem, changes in the clearance between the axial fan and the rotor are discussed. As shown in Figure 8, the distance $L$ of the original design between the two axial fans is $1430 \mathrm{~mm}$, while the rotor length is $1147 \mathrm{~mm}$.

Figure 9 depicts the relationships of the internal flow rate $Q_{2}$ and the flow rate ratio, $Q_{2} / Q_{1}$, with clearance ranging from $203 \mathrm{~mm}$ to $313 \mathrm{~mm}$. An optimum distance between the axial fan and the rotor exists. As seen in Figure 9, the optimum distance is $253 \mathrm{~mm}$, and the flow rate has a maximum value of $2.35 \mathrm{~m}^{3} / \mathrm{s}$. At the optimum distance, the flow rate ratio is $84 \%$, meaning that the maximum internal air $Q_{2}$ into the shaft, stator, and rotor has the best cooling ability, since the air leakage $Q_{3}$ is the smallest. As the clearance becomes larger than the optimum clearance, the larger space between the axial fan and the rotor increases the air leakage, which decreases the flow rate $Q_{2}$. When the distance becomes smaller than the optimum distance, the small channel between the axial fan and the rotor increases the flow resistance, which reduces the air flowing to the stator and the rotor.

Through the new design of guide vanes, shown in Figure 6(b), and the optimum distance of $253 \mathrm{~mm}$ between the rotor and the axial fan, the temperature profiles of the stator and rotor are also recalculated. As listed in Tables 4 and 5 , the temperatures decrease $3^{\circ} \mathrm{C}$ at cross Section 1 and $5^{\circ} \mathrm{C}$ at cross Section 4 . For cross Sections 2 and 3, the temperatures also decrease $5^{\circ} \mathrm{C}$.

\section{Conclusions}

This article experimentally and numerically investigates the thermal performance of a $2350-\mathrm{kW}$ enclosed air-toair cooled motor. The fan performances and temperatures of the heat exchanger, rotor, and the stator are numerically determined, which are in good agreement with the experimental data. Due to the nonuniform behavior of the external air and air leakage of the internal air, the original motor design cannot operate at the best conditions. The 
TABLE 5: Numerical results of average temperatures for the rotor.

\begin{tabular}{ccccc}
\hline & \multicolumn{2}{c}{ Iron core $\left({ }^{\circ} \mathrm{C}\right)$} & \multicolumn{2}{c}{ Copper winding $\left({ }^{\circ} \mathrm{C}\right)$} \\
\hline Cross section & Simulation & & Simulation \\
& Original design & Modified design & Original design & Modified design \\
1 & 71 & 68 & 130 & 95 \\
2 & 107 & 102 & 130 & 125 \\
3 & 107 & 102 & 108 & 103 \\
4 & 82 & 77 & & 103 \\
\hline
\end{tabular}

designs with modified guide vanes and optimum clearance between the rotor and the axial fan demonstrate that the temperatures of the rotor and stator can decrease $5^{\circ} \mathrm{C}$. The new design of the guide vanes makes the flow distributions uniform. Two axial fans with optimal distance operate at the maximum flow rate into the shaft, stator, and rotor, which increases the cooling ability. The present results provide useful information to designers regarding the complex flow and thermal interactions in large-scale motors.

\section{Nomenclature}

A: Heat transfer area, $\mathrm{m}^{2}$

$C_{p}:$ Specific heat, $\mathrm{J} / \mathrm{kg} \cdot \mathrm{K}$

M: Torque, $\mathrm{N}-\mathrm{m}$

m: Mass flow rate, $\mathrm{kg} / \mathrm{s}$

$N$ : Rotating speed, rpm

$\mathrm{O}_{p}$ : Power input, $\mathrm{kW}$

Q: Volumetric flow rate, $\mathrm{m}^{3} / \mathrm{s}$

Q: Heat generation rate, $\mathrm{W}$

T: Temperature, ${ }^{\circ} \mathrm{C}$

$U$ : Heat transfer coefficient, $\mathrm{W} / \mathrm{m}^{2} \cdot \mathrm{K}$.

\section{Greek Symbols}

$\omega:$ Angular velocity, rad/s.

\section{Subscripts}

$\begin{array}{ll}c: & \text { Cold external air } \\ h: & \text { Hot internal air } \\ i: & \text { Inner } \\ \text { In: } & \text { Inlet } \\ o: & \text { Outer } \\ \text { Out: } & \text { outlet. }\end{array}$

\section{Acknowledgments}

The authors thank China Steel Corporation and Tatung Corporation for supporting this project.

\section{References}

[1] R. S. Amano, E. K. Lee, C. Xu, and J. Xie, "Investigation of the unsteady flow generated by an axial fan: experimental testing and simulations," International Journal of Rotating Machinery, vol. 2005, no. 3, pp. 256-263, 2005.
[2] M. Younsi, F. Bakir, S. Kouidri, and R. Rey, "Influence of impeller geometry on the unsteady flow in a centrifugal fan: numerical and experimental analyses," International Journal of Rotating Machinery, vol. 2007, Article ID 34901, 10 pages, 2007.

[3] W. Zhou, Z. Zhao, T. S. Lee, and S. H. Winoto, "Investigation of flow through centrifugal pump impellers using computational fluid dynamics," International Journal of Rotating Machinery, vol. 9, no. 1, pp. 49-61, 2003.

[4] M. Asuaje, F. Bakir, S. Kouidri, F. Kenyery, and R. Rey, "Numerical modelization of the flow in centrifugal pump: volute influence in velocity and pressure fields," International Journal of Rotating Machinery, vol. 2005, no. 3, pp. 244-255, 2005.

[5] F. P. Bleier, Fan Handbook: Selection, Application, and Design, McGraw-Hill, New York, NY, USA, 1997.

[6] C. M. Liao, C. L. Chen, and T. Katcher, "Thermal management of AC induction motors using computational fluid dynamics modeling," in Proceedings of the International Conference on Electric Machines and Drives (IEMD '99), pp. 189-191, Seattle, Wash, USA, 1999.

[7] C. M. Liao and C. L. Chen, "Thermal analysis and design for power electronics of integrated motor," in Proceedings of the International Symposium on Microelectronics, vol. 3906 of Proceedings of SPIE, pp. 408-414, Chicago, Ill, USA, October 1999.

[8] W. Mei, M. A. Jabbar, and A. A. O. Tay, "Determination of thermal performance of small electric motors," in Proceedings of the International Conference on Power Electronics and Drive Systems, vol. 2, pp. 877-880, October 2001.

[9] A. Zuksuskas and R. Ulinskas, "Banks of plain and finned tubes," in Heat Exchanger Design Handbook, G. F. Hewitt, Ed., chapter 2.2.4, Begell House, 1998.

[10] P. I. Frank, Fundamentals of Heat and Mass Transfer, John Wiley \& Sons, New York, NY, USA, 4th edition, 1996. 

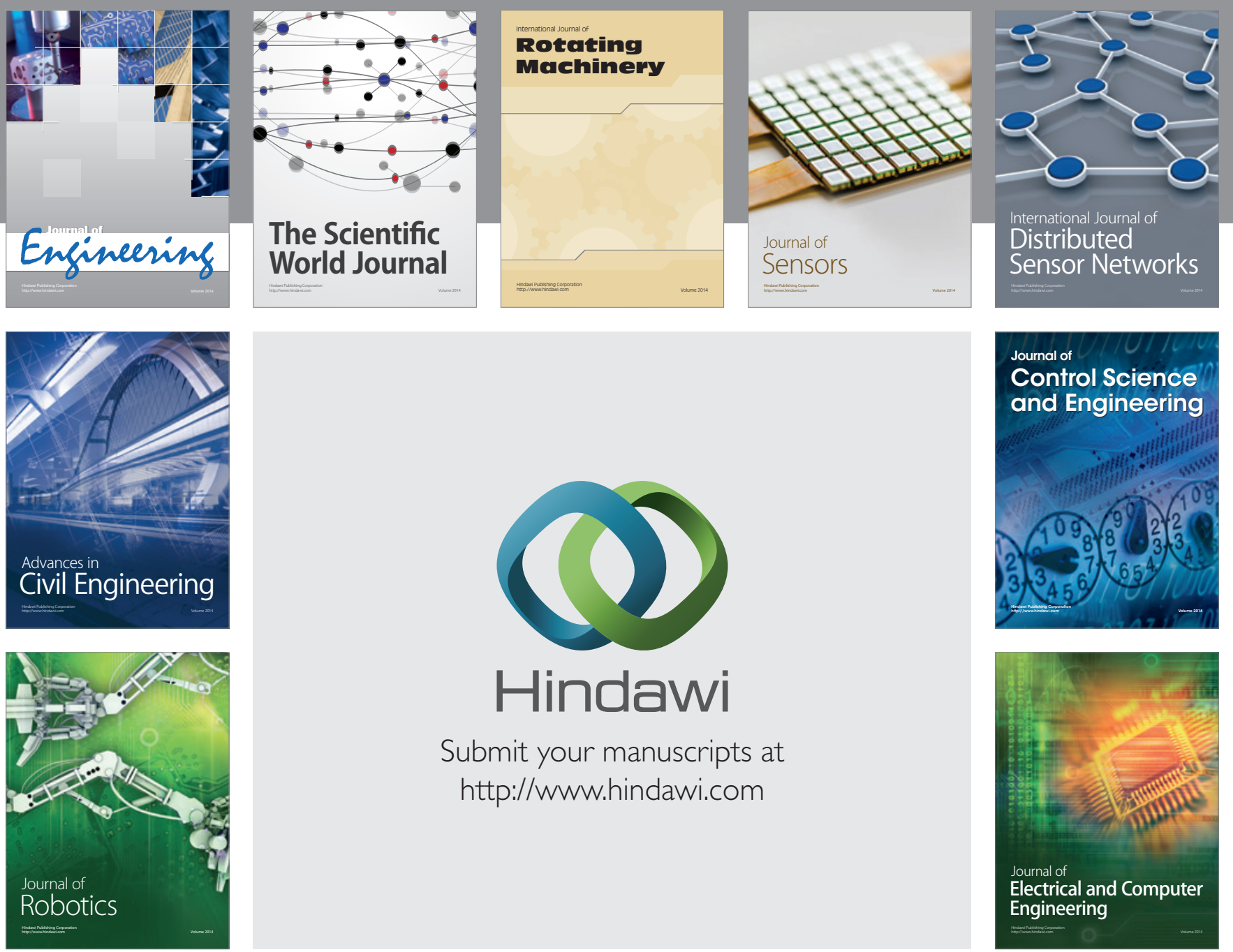

Submit your manuscripts at

http://www.hindawi.com
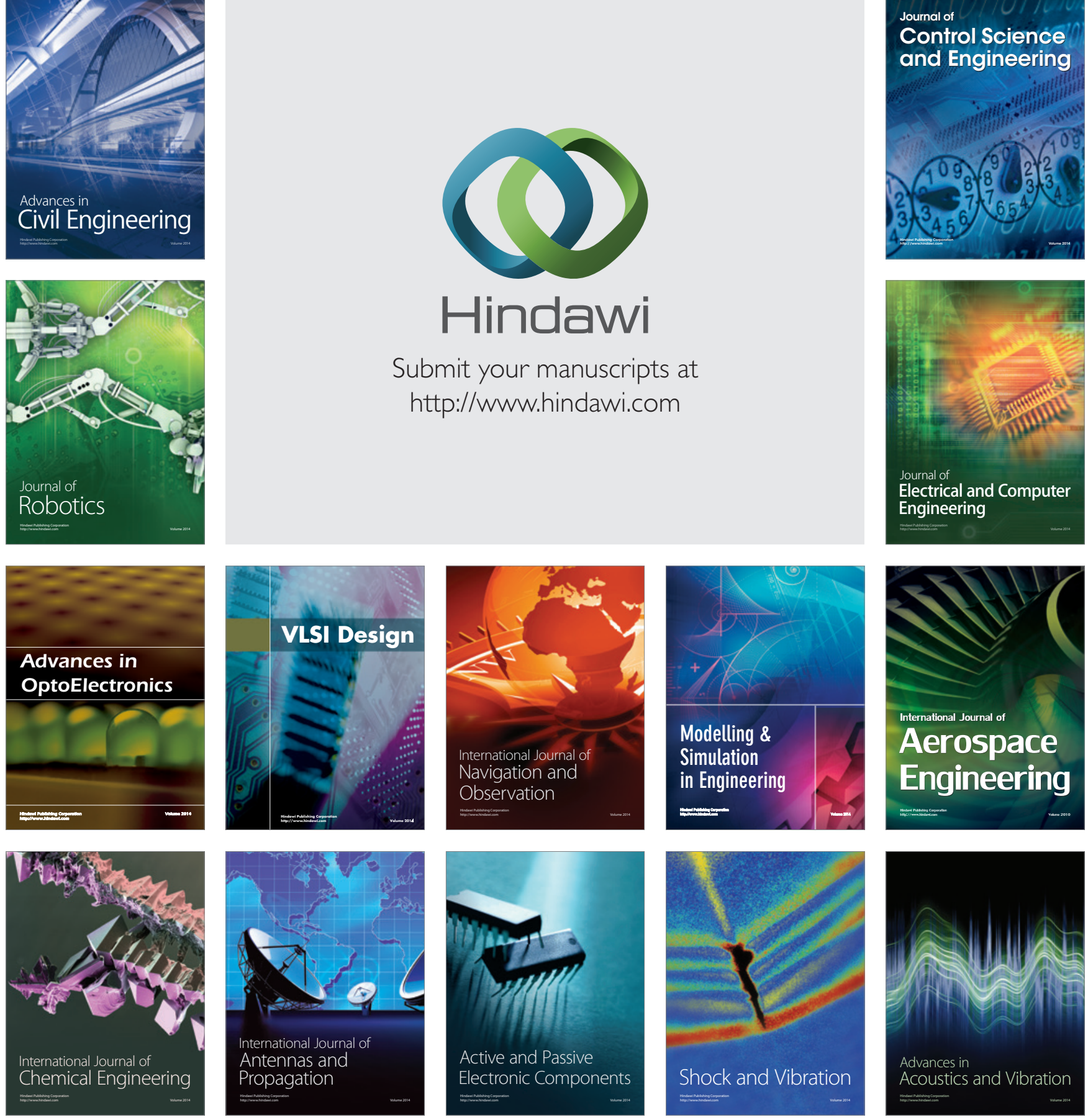